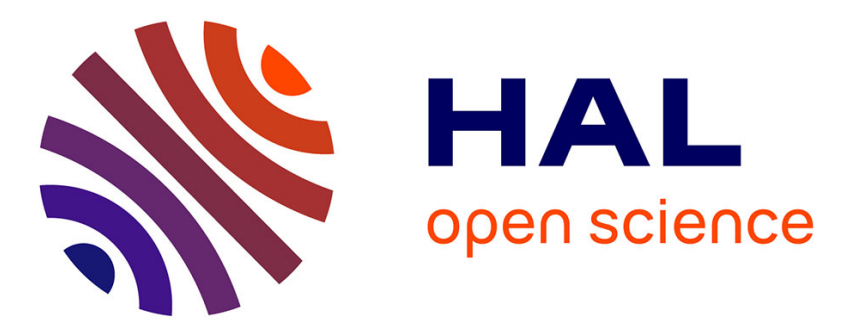

\title{
Electronic and magnetic properties of yttria-stabilized zirconia (6.7 mol\% in Y2O3) doped with Er3+ ions from first-principle computations
}

\author{
Hassan Denawi, Panaghiotis Karamanis, Michel Rérat
}

\section{To cite this version:}

Hassan Denawi, Panaghiotis Karamanis, Michel Rérat. Electronic and magnetic properties of yttriastabilized zirconia (6.7 mol\% in Y2O3) doped with Er3+ ions from first-principle computations. Journal of Materials Science, 2021, 56, pp.8014-8023. 10.1007/s10853-021-05793-6 . hal-03128051

\section{HAL Id: hal-03128051 \\ https://hal.science/hal-03128051}

Submitted on 2 Feb 2021

HAL is a multi-disciplinary open access archive for the deposit and dissemination of scientific research documents, whether they are published or not. The documents may come from teaching and research institutions in France or abroad, or from public or private research centers.
L'archive ouverte pluridisciplinaire HAL, est destinée au dépôt et à la diffusion de documents scientifiques de niveau recherche, publiés ou non, émanant des établissements d'enseignement et de recherche français ou étrangers, des laboratoires publics ou privés. 


\title{
Electronic and magnetic properties of yttria-stabilized zirconia (6.7 mol\% in $\mathrm{Y}_{2} \mathrm{O}_{3}$ ) doped with $\mathrm{Er}^{3+}$ ions from first-principle computations
}

\author{
Hassan Denawi ${ }^{1}$, Panaghiotis Karamanis ${ }^{1}$, and Michel Rérat ${ }^{1, *}$ (]) \\ ${ }^{1}$ Université de Pau et des Pays de L'Adour, CNRS, IPREM UMR 5254, 64053 Pau, France
}

Received: 4 August 2020

Accepted: 8 January 2021

(C) Springer Science+Business Media, LLC, part of Springer Nature 2021

\begin{abstract}
Yttria-stabilized zirconia (YSZ) is a widely recognized ceramic of distinct electrical, mechanical and optical properties. Although YSZ is an intrinsically paramagnetic solid, it could potentially transform to a magnetic semiconductor by incorporating in its crystalline structure isolated atoms bearing unpaired valence electrons. Based on this hypothesis and motivated by the latest advances on YSZ doped with rare-earth atoms, in the current article we report on the electronic and magnetic properties of YSZ doped with $\mathrm{Er}^{3+}\left([\mathrm{Xe}] 4 \mathrm{f}^{11} 6 \mathrm{~s}^{0}\right)$ cations that comprise three "unpaired" $4 \mathrm{f}$ electrons in their ground state electronic configuration. Our computations, conducted on YSZ $6.7 \mathrm{~mol} \%$ in $\mathrm{Y}_{2} \mathrm{O}_{3}$ doped with two different $\mathrm{Er}^{3+}$ concentrations ( 3.2 and $6.7 \mathrm{~mol} \%$ in $\mathrm{Er}_{2} \mathrm{O}_{3}$ ), expose that $\mathrm{Er}^{3+}: \mathrm{YSZ}$ is a stable antiferromagnetic semiconductor $\left(S=\frac{3}{2}\right.$ per $\left.\mathrm{Er}^{+3}\right)$ bearing a rather wide band gap of about $5 \mathrm{eV}$. All results presented and discussed in current report rely on spinpolarized density functional theory (DFT) within the spin resolved generalized gradient approximation (SGGA) for the pure Perdew, Burke and Ernzerhof exchange-correlation functional (PBE) and hybrid version widely referred as PBE0. According to our knowledge, this is the first time that the magnetic properties of $\mathrm{Er}^{3+}$ : YSZ materials are reported for any $\mathrm{Er}^{+3}$ concentration.
\end{abstract}

\section{Introduction}

It is a common sense that semiconductors stand as the cornerstone of current technologies applied in the realms of telecommunications, light-emitting diodes
(LEDs), lasers, integrated sensors [1-7] and spintronics [8, 9]. In particular, for the latter class of applications that seeks to exploit the spin of charge carriers incorporated in the crystal framework of a given solid [10-13], diluted magnetic semiconductors

Handling Editor: Avinash Dongare.

Hassan Denawi and Panaghiotis Karamanis have contributed equally.

Address correspondence to E-mail: michel.rerat@univ-pau.fr

https:/ / doi.org/10.1007/s10853-021-05793-6 
have emerged as very promising candidates attracted considerable attention the past decades [11, 14-18].

Yttria-stabilized zirconia (YSZ) is an extrastable wide band gap functional oxide of high mechanical, chemical and thermal stability [19-31]. A considerable part of its properties are related to the presence of structural oxygen vacancies, created as yttrium cations are incorporated to zirconia dioxide to stabilize its cubic phase in room temperature [32-34]. In particular, YSZ crystals doped with erbium ions have attracted the interest of many researchers in recent years owed to their promising electro-optical properties [35-43]. For instance, Greenberg et al. [36] and Savoini et al. [41] studied the spectroscopic properties of YSZ crystal doped with $\mathrm{Er}^{3+}$ ions via optical absorption and emission spectroscopy including lifetime measurements and pointed out Er-doped YSZ is excellent candidate for advanced applications photonics. The spectral and luminescent characteristics of $\mathrm{Er}^{+3} \mathrm{YSZ}(6 \mathrm{~mol} \%$ in $\mathrm{Y}_{2} \mathrm{O}_{3}, 2 \mathrm{~mol} \%$ in $\mathrm{Er}_{2} \mathrm{O}_{3}$ ) have been studied by $\mathrm{X}$. Wang et al.[43] while P. Ryabochkina et al. [40] studied $\mathrm{Er}^{+3} \mathrm{YSZ}$ (6 mol\% in $\mathrm{Y}_{2} \mathrm{O}_{3}, 5.85 \%$ in $\mathrm{Er}_{2} \mathrm{O}_{3}$ ) as potential active media of solid state laser emitters in a wavelength range of 1.5-1.7 $\mu \mathrm{m}$. Furthermore, Caridad et al. [44] starting from $8 \mathrm{~mol} \%$ in $\mathrm{Y}_{2} \mathrm{O}_{3} \mathrm{YSZ}$ engineered recently high-purity $\mathrm{Er}^{3+}: \mathrm{YSZ}$ thin films and characterized their optical properties. As those authors point out, high-purity $\mathrm{Er}^{3+}$ :YSZ films could find a proper ground in hybrid photonic platforms involving on-chip optical amplification at telecommunication wavelengths $(\sim 1500 \mathrm{~nm})$. Finally, there are also several studies reporting the doping of other solids with $\mathrm{Er}^{3+}$, for instance, $\mathrm{In}_{2} \mathrm{O}_{3}$ [45], $\mathrm{SnO}_{2}$ [46] and pure $\mathrm{ZrO}_{2}$ [47].

Motivated by the increasing interest in materials built from Er-doped YSZ, in the current article we report on the electronic structure and magnetic properties of $\mathrm{YSZ} 6.7 \mathrm{~mol} \%$ in $\mathrm{Y}_{2} \mathrm{O}_{3}$ doped with two different concentration $\mathrm{Er}_{2} \mathrm{O}_{3}(3.2 \mathrm{~mol} \%$ and $6.7 \mathrm{~mol}$ $\%)$. Our aim is to obtain a reliable description of the electronic properties of this appealing material at the atomic level and determine the influence of $\mathrm{Er}^{3+}$ on its magnetic properties.

\section{Theoretical methods and computational details}

\section{Crystal atomistic structures construction}

Although theoretical simulations [48] suggest that YSZ with $3.2 \mathrm{~mol} \%$ in $\mathrm{Y}_{2} \mathrm{O}_{3}$ should be regarded as the minimum concentration of $\mathrm{Y}_{2} \mathrm{O}_{3}$ required to stabilize the cubic phase of $\mathrm{ZrO}_{2}$ in room temperature, most of the recent experimental investigations are routinely performed at higher concentration of about $8 \mathrm{~mol} \%$ in $\mathrm{Y}_{2} \mathrm{O}_{3}$ [49]. Nevertheless, the construction of an YSZ cell model of precisely $8 \mathrm{~mol} \%$ in $\mathrm{Y}_{2} \mathrm{O}_{3}$ would require an extra-large $\mathrm{c}-\mathrm{ZrO}_{2}$ supercell of more than 190 atoms. Therefore, for the sake of computational efficiency [24] we conducted our investigation on a periodic model of YSZ with $6.7 \mathrm{~mol} \%$ yttria (instead of $8 \mathrm{~mol} \%$ ) assuming that $1.3 \mathrm{~mol} \%$ concentration difference would have a minor impact on the properties of interest. Such a modeling choice, adopted also in earlier computations studies, considerably reduces the size of the required supercell simply because YSZ doped with $6.7 \mathrm{~mol} \%$ in $\mathrm{Y}_{2} \mathrm{O}_{3}$ can be easily built by introducing two $\mathrm{Y}_{2} \mathrm{O}_{3}$ units into a $2 \times 2 \times 2$ supercell of a 96-atom conventional crystallographic $\mathrm{c}-\mathrm{ZrO}_{2}$ supercell. Even in that case thought, the determination of the most stable configurations remains a challenging computational task. Specifically, to conclude to the most stable local atomistic crystal structure one should systematically remove two oxygen atoms and replace any four zirconium ions with an equal number of charge-compensating $\mathrm{Y}$ ions. If this strategy is applied to a $2 \times 2 \times 2$ supercell, an extremely large set of initial nonequivalent local atomistic crystal structures (> 2500) should be generated [24]. To circumvent this hampering point, we relied on the structural data of YSZ proposed by Parkes et al. [24]. These authors have studied $\mathrm{YSZ} 6.7 \%$ in $\mathrm{Y}_{2} \mathrm{O}_{3}$ by means of gradient corrected DFT and proposed a data set of stable local atomistic structures. Starting from the most stable structure of YSZ proposed by these authors, we constructed six additional independent configurations of YSZ and we reoptimized their atomistic structures at PBE and PBE0 levels of theory. After the most stable structure of YSZ was determined within this set of trial configurations, we added two and four erbium atoms to the YSZ supercell (see Fig. 1). In such a manner, two $\mathrm{Er}^{3+}$ :YSZ models of $3.2 \mathrm{~mol} \%$ 


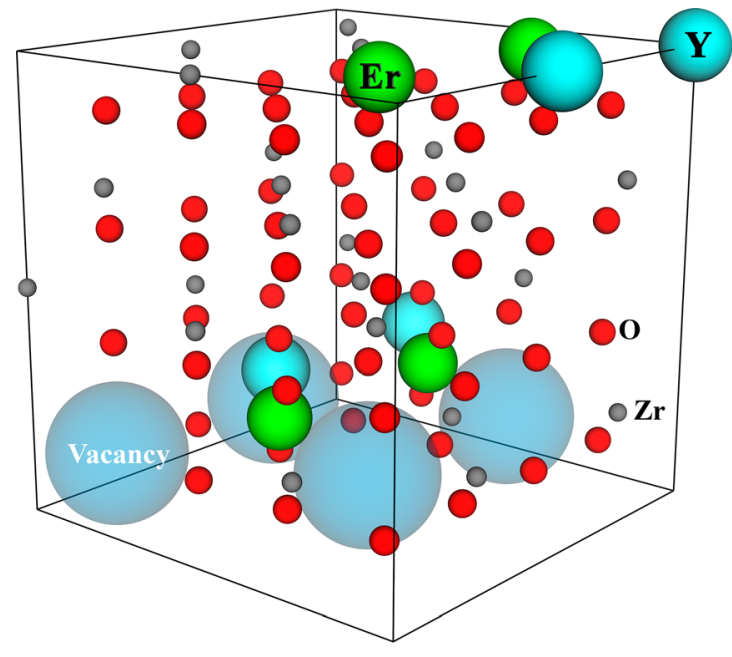

$6.7 \% \mathrm{YSZ}-6.7 \% \mathrm{Er}_{2} \mathrm{O}_{3}$

Figure 1 Local atomistic structures of the erbium-doped yttriastabilized zirconia used in this work built on $2 \times 2 \times 2$ supercell of $\mathrm{ZrO}_{2}$. Both supercells have been optimized at the PBE level of

and $6.7 \mathrm{~mol} \%$ in $\mathrm{Er}_{2} \mathrm{O}_{3}$, respectively, have been constructed to study the influence of $\mathrm{Er}^{+3}$ concentration.

\section{Computational methods}

All theoretical calculations have been performed within the framework of spin-polarized Density Functional Theory (DFT) and the PAW method $[50,51]$ as implemented in the Vienna ab initio simulation package (VASP) code [52-54]. Brillouin zone sampling has been performed using a $4 \times 4 \times 4$ Monkhorst-Pack (MP) [55] grid in both the $2 \times 2 \times 2$ supercell of $\mathrm{c}-\mathrm{ZrO}_{2}$ and the erbium-doped YSZ. The Gaussian smearing method was used in these calculations, in a width of $0.01 \mathrm{eV}$. The electronic wave functions were expanded in plane waves with a kinetic energy cutoff of $550 \mathrm{eV}$. In all cases, the bulk super-cells were relaxed until the residual forces were below $10^{-4} \mathrm{eV} / \AA$ and the convergence criteria for the energy deviations were $10^{-5} \mathrm{eV}$. Bader charge analysis [56-58] was performed on the all-electron charge density (the core density was generated from the pseudo potentials files) in order to evaluate the charge of all atoms of the $\mathrm{Er}^{+3} \mathrm{YSZ}$ supercells considered.

Being aware of the well-known deficiencies of conventional pure DFT [59] in describing strongly correlated systems, we chose the hybrid PBE0, HSE06 and the pure PBE functionals, respectively. In the

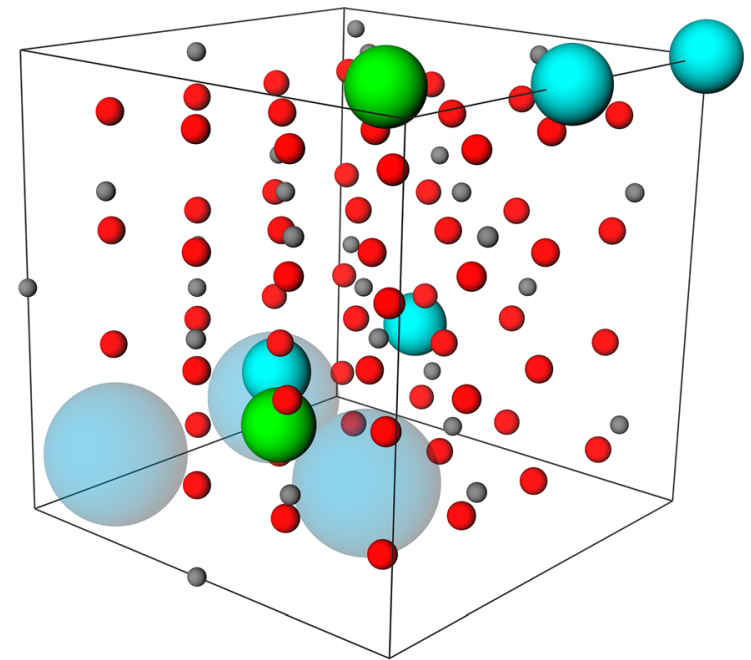

$6.7 \% \mathrm{YSZ}-3.2 \% \mathrm{Er}_{2} \mathrm{O}_{3}$

theory without relaxation of the supercell lattice constants. The $\mathrm{O}$ vacancy sites are oriented along the (210) direction, with an atomic site separation of is $5.73 \AA$.

latter approximation, the Hubbard correction term has been also employed [60-64]. In all cases, we applied the spin-polarized generalized gradient approximation (SGGA + U) correction scheme introduced by Liechtenstein et al. [65] where the widely applied correction parameters $U$ and $J$ are implemented as independent corrections. Specifically, the parameter $U$ corresponds to the required energy for the addition of an additional charge to the $4 d$ and $4 f$ shell in the atomic limit. On the other hand, J parameter describes the intra-atomic screened exchange interaction. Here, we have chosen a value of $U=7 \mathrm{eV}$ and $J=0.9 \mathrm{eV}$ that have been conventionally added based on the properties of the Er, Y, Zr atoms after extensive benchmark bandgap calculations performed on pure $\mathrm{c}-\mathrm{ZrO}_{2}$.

\section{Results and discussion}

Charge distribution, bonding and energy difference between the conduction and valence bands of $\mathrm{Er}^{+3}$ :YSZ $3.2 \mathrm{~mol} \%$ and $6.7 \mathrm{~mol} \%$ in $\mathrm{Er}_{2} \mathrm{O}_{3}$

To obtain some first insights about the bonding in YSZ $3.2 \mathrm{~mol} \%$ and $6.7 \mathrm{~mol} \%$ in $\mathrm{Er}_{2} \mathrm{O}_{3}$ at the atomic level, we computed and studied the net charges of each atom by applying the Bader partitioning 
scheme as implemented in VASP code. Based on carefully chosen topological properties, the latter method partitions the space of a given cell in distinct regions encasing each nucleus and attributes net charges to each of them. The results listed in Table 1 and visualized in Fig. 2 point out that the net atomic charges should be identical for both concentrations of $\mathrm{Er}_{2} \mathrm{O}_{3}$ in YSZ. Specifically, relying on the computed valence occupation numbers, the atomic charges of Er, $\mathrm{Y}, \mathrm{Zr}$ and $\mathrm{O}$ should lie at $+2.0,+2.1,+2.6$ and -1.3 , electrons, respectively. This result suggests that the net charge of Er ions should be closer to +2 than +3 as chemical intuition would suggest in terms of the expected oxidation degree of $\mathrm{Er}$ in isolated $\mathrm{Er}_{2} \mathrm{O}_{3}$. The latter result is in line with the computed atomic change on oxygen atoms which is found around $\mathrm{O}-1.3 \mathrm{e}$, (instead of -2.0 ) if we consider that the embedded $\mathrm{Er}_{2} \mathrm{O}_{3}$ should remain neutral. To verify this outcome, we recomputed the atomic charges using Mulliken population analysis at the PBE0 level of theory and a pseudopotential basis set of gaussian type functions for all atoms, as implemented in the CRYSTAL 17 suite of programs [66]. In this case, we obtained a charge of $+2.6 \mathrm{e}$ for $\mathrm{Er},+2.1 \mathrm{e}$ for $\mathrm{Zr},+2.3 \mathrm{e}$ for $\mathrm{Y}$ and $-1.3 \mathrm{e}$ in the case of $\mathrm{O}$. As it becomes obvious, neither method attributes an absolute net charge of $+3 e$ to the embedded Er atoms. The observed differences might stem either from limitations of the methods used in the description of each atom in the environment of the supercell considered and/or to non-negligible covalent contributions in the intracell bonding. For instance, a careful electron population analysis of each atom in the supercells considered revealed that the reduced positive atomic charge of Er cations in the case of Bader partitioning should stem from additive $\rho_{\alpha}$ and $\rho_{\beta}$ electron densities with $\rho_{\alpha}+\rho_{\beta} \sim 1$ and $\rho_{\alpha} \sim \rho_{\beta}$ which "appear" in the $5 d$ atomic orbitals of Er.

Table 1 Number of valence electrons $\left(\mathrm{V}^{0}\right)$ of the free atoms Er, $\mathrm{Y}$, $\mathrm{Zr}$ and $\mathrm{O}$ and Bader valence electron $\left(\mathrm{V}^{\mathrm{B}}\right)$ of each atom in a $2 \times 2 \times 2$ supercell of Er: ${ }^{+3} \mathrm{YSZ}$ and their differences $(\Delta \mathrm{V})$

\begin{tabular}{lllll}
\hline & $\mathrm{Er}$ & $\mathrm{Y}$ & $\mathrm{Zr}$ & $\mathrm{O}$ \\
\hline $\mathrm{V}^{0}$ & 22 & 11 & 12 & 6 \\
$\mathrm{~V}^{\mathrm{B}}$ & 20.0 & 8.9 & 9.4 & 7.3 \\
$\Delta \mathrm{V}$ & +2.0 & +2.1 & +2.6 & -1.3 \\
\hline
\end{tabular}

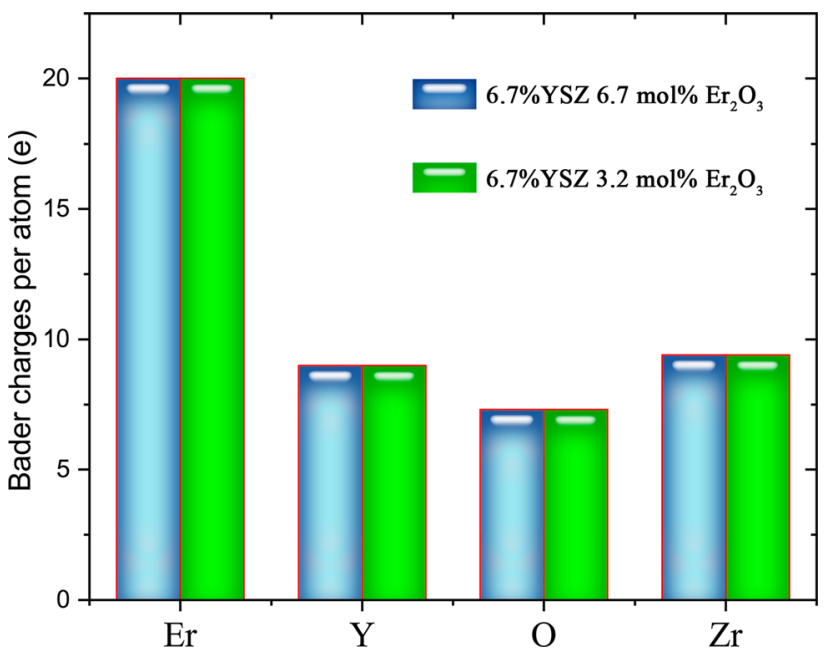

Figure 2 Charge distribution for all atoms in the states of YSZ$\mathrm{Er}_{2} \mathrm{O}_{3}$ computed by the Bader charge analysis method.

Let us now turn our attention to the data listed in Table 2, where we compare the computed bandgap of $\mathrm{Er}^{+3}$ :YSZ with those of $\mathrm{c}-\mathrm{ZrO}_{2}$ and YSZ $6.7 \mathrm{~mol} \%$ $\mathrm{Y}_{2} \mathrm{O}_{3}$, at four levels of theory. As seen, for pure $\mathrm{c}-\mathrm{ZrO}_{2}$ and $\mathrm{YSZ}$, out of the four methods considered here, PBE0 returns the most accurate values with respect to the experiment. Specifically, the PBE0 band gap of pure $\mathrm{c}-\mathrm{ZrO}_{2}$ (YSZ) is found about $6.11 \mathrm{eV}$ $(5.65 \mathrm{eV})$ while the available experimental values vary between 6.10 and $7.08 \mathrm{eV}[67,68](5.8 \mathrm{eV})$ [23]. On the other hand, the PBE method undershoots considerably the experimental values. Despite the observed differences between various methods considered, all functionals conclude to the same trend according to which the bandgap of YSZ undergoes a rather weak decrease upon Er doping.

\section{Magnetic properties of $\mathrm{Er}^{+3}: \mathrm{YSZ}$}

In Table 3, we compare the energy differences between various spin states, namely nonmagnetic (NM), ferromagnetic (FM) and antiferromagnetic (AFM), of $\mathrm{Er}^{3+}: \mathrm{YSZ} 3.2,6.7 \mathrm{~mol} \%$ in $\mathrm{Er}_{2} \mathrm{O}_{3}$. A careful study of the computed values suggests that the (A) FM states of $\mathrm{Er}^{3+}$ :YSZ should lie considerably lower in energy than their nonpolarized counterpart. Depending on the functional used, the exchange energies $\left(\Delta_{E_{\mathrm{NM}}-E_{\mathrm{FM}}}\right)$ vary from a minimum of $1.58 \mathrm{eV}$ (PBE) to a maximum of $5.83 \mathrm{eV}(\mathrm{PBE}+\mathrm{U})$. On the other hand, HSE06 and PBE0 approximations return energy differences of $4.85 \mathrm{eV}$ and $4.89 \mathrm{eV}$, respectively, that lie closer but lower to the $\mathrm{PBE}+\mathrm{U}$ 
Table 2 Computed energy band gaps $(\mathrm{Eg}$, in eV) of $32 \mathrm{ZrO}_{2}$, YSZ and $\mathrm{YSZ}-\mathrm{Er}_{2} \mathrm{O}_{3}$ where FM (AFM) stands for (anti)ferromagnetic spin distributions

\begin{tabular}{|c|c|c|c|c|c|}
\hline & PBE & $\mathrm{PBE}+\mathrm{U}$ & HSE06 & PBE0 & Exp. [23, 67] \\
\hline $\mathrm{ZrO}_{2}$ & 3.20 & 4.32 & 5.42 & 6.11 & $6.10-7.08$ \\
\hline $\mathrm{YSZ}^{6.7 \% \mathrm{Y}_{2} \mathrm{O}_{3}}$ & 3.10 & 3.77 & 4.89 & 5.65 & 5.8 \\
\hline $\mathrm{Er}^{+3}: \mathrm{YSZ}^{3.2 \%} \mathrm{Er}_{2} \mathrm{O}_{3}(\mathrm{FM})$ & - & 3.55 & 4.42 & 5.19 & - \\
\hline 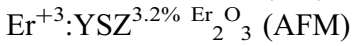 & - & 3.57 & 4.46 & 5.20 & - \\
\hline $\mathrm{Er}^{+3}: \mathrm{YSZ}^{6.7 \%} \mathrm{Er}_{2} \mathrm{O}_{3}(\mathrm{FM})$ & - & 3.71 & 4.59 & 5.31 & - \\
\hline $\mathrm{Er}^{+3}: \mathrm{YSZ}^{6.7 \% \mathrm{Er}_{2} \mathrm{O}_{3}}(\mathrm{AFM})$ & - & 3.75 & 4.61 & 5.37 & - \\
\hline
\end{tabular}

Table 3 Exchange energies $\left(\Delta_{E_{\mathrm{NM}}-E_{\mathrm{FM}}}\right.$, per Er atom, in $\mathrm{eV}$ and $\Delta_{E_{\mathrm{FM}}-E_{\mathrm{AFM}}}$, per Er atom, in meV), local magnetic moments at the Er atoms $\left(M_{E r}\right.$ per Er atom, in $\left.\mu_{B}\right)$ and magnetic anisotropy energy (MAE, in $\mathrm{meV}$ ) of $32 \mathrm{ZrO}_{2}, \mathrm{YSZ}$ and $\mathrm{YSZ}-\mathrm{Er}_{2} \mathrm{O}_{3}$. The notation $\uparrow$ means $\mathrm{S}_{\mathrm{z}}=3 / 2$ on each Er. In all cases, a complete relaxation of all nuclear positions in the cell has been performed to assure the reliability of the results

\begin{tabular}{|c|c|c|c|c|}
\hline & PBE & $\mathrm{PBE}+\mathrm{U}$ & HSE06 & PBE0 \\
\hline & \multicolumn{4}{|c|}{$\mathrm{YSZ}^{3.2 \mathrm{~mol} \% \mathrm{Er}_{2} \mathrm{O}_{3}}$} \\
\hline$\Delta_{E_{\mathrm{NM}}-E_{\mathrm{FM}}}$ & 1.58 & 5.83 & 4.85 & 4.89 \\
\hline$\Delta_{E_{\mathrm{AFM}}-E_{\mathrm{FM}}}$ & -0.87 & -0.10 & -0.17 & -0.19 \\
\hline \multirow[t]{2}{*}{$M_{\mathrm{Er}}$} & 2.87 & 2.99 & 2.96 & 2.96 \\
\hline & \multicolumn{4}{|c|}{$\mathrm{YSZ}^{6.7 \mathrm{~mol} \% \mathrm{Er}_{2} \mathrm{O}_{3}}$} \\
\hline$\Delta_{E_{\mathrm{AFM}(\uparrow \uparrow \downarrow \downarrow)}-E_{\mathrm{FM}(\uparrow \uparrow \uparrow \uparrow)}}$ & 1.64 & 0.16 & 0.11 & 0.10 \\
\hline$\Delta_{E_{\mathrm{AFM}(\uparrow \downarrow \uparrow \downarrow)}}-E_{\mathrm{FM}(\uparrow \uparrow \uparrow \uparrow)}$ & -0.07 & -0.02 & -0.17 & -0.40 \\
\hline$\Delta_{E_{\mathrm{AFM}(\uparrow \downarrow \uparrow \downarrow)}-E_{\mathrm{AFM}(\uparrow \uparrow \downarrow \downarrow)}}$ & -1.71 & -0.18 & -0.28 & -0.50 \\
\hline$M_{\mathrm{Er}}$ & 2.86 & 2.99 & 2.96 & 2.96 \\
\hline$M_{\mathrm{Er}}(x)$ & 2.74 & 2.87 & - & - \\
\hline$M_{\mathrm{Er}}(y)$ & 2.73 & 2.87 & - & - \\
\hline$M_{\mathrm{Er}}(z)$ & 2.70 & 2.87 & - & - \\
\hline $\operatorname{MAE}\left(\Delta_{E_{x}-E_{y}}\right)$ & 5.03 & 4.97 & - & - \\
\hline $\operatorname{MAE}\left(\Delta_{E_{x}-E_{z}}\right)$ & 5.04 & 7.42 & - & - \\
\hline
\end{tabular}

method. Therefore, for the lowest concentration of $3.2 \mathrm{~mol} \%$ in $\mathrm{Er}_{2} \mathrm{O}_{3}$ and regardless of the method chosen, the FM state appears to be the most stable one. Turning our attention to the energy differences between the FM and AFM states corresponding to the latter concentration, we see also that all methods predict that the AFM lies lower in energy than FM. In this case, the PBE pure functional returns the largest energy differences $(0.87 \mathrm{meV})$ while the smallest one is returned by $\mathrm{PBE}+\mathrm{U}$ approximation. Conversely, the two hybrid functionals considered here deliver energy differences of 0.17 and $0.19 \mathrm{meV}$. Consequently, $\mathrm{Er}^{3+}: \mathrm{YSZ} 3.2 \mathrm{~mol} \%$ in $\mathrm{Er}_{2} \mathrm{O}_{3}$ at $0 \mathrm{~K}$ should be safely considered as a magnetic semiconductor with the corresponding (A)FM states lying very close in energy. Focusing now our attention to the computed data of Table 3 obtained for $\mathrm{Er}^{3+}: \mathrm{YSZ}$ $6.7 \mathrm{~mol} \%$ in $\mathrm{Er}_{2} \mathrm{O}_{3}$, we see that an almost twofold increase in $\mathrm{Er}^{+3}$ concentration (from 3.2 to $6.7 \mathrm{~mol} \%$ ) might have a small but worth noticing effect on the energetic ordering between the FM and the two possible AFM states of different spin distributions. Specifically, our outcomes suggest that for the later concentration (comprising four $\mathrm{Er}^{+3} /$ supercell) the AFM $[\operatorname{Er}(\uparrow) \operatorname{Er}(\downarrow) \operatorname{Er}(\uparrow) \operatorname{Er}(\downarrow)]$ state, where each arrow represents a spin of $3 / 2$, is the most stable one. Specifically, at PBE0 level the latter state lies about 0.4 and $0.5 \mathrm{meV}$ lower in energy than the corresponding $[\operatorname{Er}(\uparrow) \operatorname{Er}(\uparrow) \operatorname{Er}(\uparrow) \operatorname{Er}(\uparrow)]$ and $[\operatorname{Er}(\uparrow) \operatorname{Er}(\uparrow) \operatorname{Er}(\downarrow) \operatorname{Er}(\downarrow)]$ spinpolarized states, respectively.

Let us now proceed with the computed atomic magnetic properties of the systems considered computed at the PBE and PBE $+U$ levels of theory which provide a better ratio between accuracy and efficiency than the two hybrids used in this study. Based on the values summarized in Table 3, we see that the total magnetic moment per cell for both AFM and FM phases and both concentrations is 0 and 6 (12) $\mu_{B}$, respectively, while the projected spin density on each $\mathrm{Er}^{+3}$ yields a magnetic moment $\left(M_{E r}\right)$ close to $3 \mu_{B}$. This result matches the expectation value for the free $\mathrm{Er}^{3+}$ ion in its ground state ([Xe] $\left.4 f^{11} 6 s^{0}\right)$ and contradicts the Bader partitioning which as we discussed in the previous section suggests that the charge of the Er atoms should be about +2.0. On the other hand, Mulliken charges seem to provide a better description of the Er net charges in this case. Finally, we computed the local magnetic moment of the erbium atom with the local spin density approximation (LSDA) by Ceperley-Alder (CA) pseudopotential [69]. The obtained result of $2.85 \mu_{\mathrm{B}}$ lies very close to those obtained with the SGGA $\left(2.86 \mu_{\mathrm{B}}\right)$ approximation.

In a further step, we calculated the magnetic anisotropy energy (MAE) of YSZ $6.7 \mathrm{~mol} \%$ in $\mathrm{Er}_{2} \mathrm{O}_{3}$ defined as the difference between the total energies of 
a magnetic material for different orientations of the magnetization. For that purpose, we used the SGGA method including spin-orbit coupling (SOC) [62] taking also into account the Hubbard term $(U)$ [63]. Our outcomes returned a slight change on the local magnetic moments by less than $0.12 \mu_{B}$. Here, it is important to mention that the atomistic local structure and the vacancy/dopant distribution and the gap energies of the systems considered are not influenced by the SO coupling. Finally, the anisotropy energies summarized in Table 3 point out that YSZ $6.7 \mathrm{~mol} \%$ in $\mathrm{Er}_{2} \mathrm{O}_{3}$ features a magnetic anisotropy of about $7.42 \mathrm{meV}$ per Er with the magnetic moment lying in the z-direction of the structure. A similar trend should be expected for the other concentration $\left(3.2 \mathrm{~mol} \%\right.$ in $\left.\mathrm{Er}_{2} \mathrm{O}_{3}\right)$ considered in this work.

For a deeper understanding of the magnetization distribution, the spin densities, defined as the difference between the spin-up and spin-down electron densities $\left(\rho_{\text {spin-up }}-\rho_{\text {spin-down }}\right)$, have been also computed and studied for both concentrations in $\mathrm{Er}_{2} \mathrm{O}_{3}$ (see Fig. 3). To provide an intuitive visualization of the spin densities, we have chosen a spin density cut through the plane of the $\mathrm{YSZ}-\mathrm{Er}_{2} \mathrm{O}_{3}$. As seen, the spin density contours that vary between -0.02 and $0.02 \AA^{-3}$, point out that the rare-earth metal sites are characterized by the highest magnetic moment

(a)

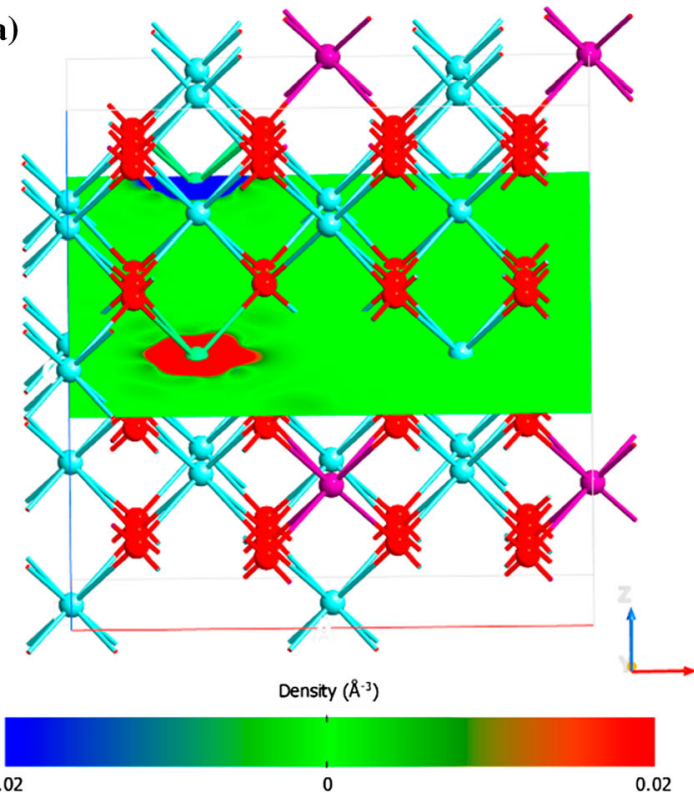

values, while their magnetic moments reach a value of about $3.0 \mu_{B}$ per Er atom. Hence, the main magnetic moment contributions are strongly localized on the Er atom (see Fig. 3) as is also suggested by the local magnetic moments listed in Table 3.

\section{Density of states}

We will close this report with a brief discussion about the character of the total and partial densities of states of the ferromagnetic state of $\mathrm{Er}^{3+}$ :YSZ starting from three spins up, $S_{z}=+3 / 2$, on each Er represented by an upward pointing arrow $(\uparrow)$. The corresponding density-of-states (DOS) plots, computed within the spin-polarized hybrid PBE0 approximation, are illustrated in Fig. 4. As it is readily seen, both $\mathrm{Er}^{3+}$ :YSZ $3.2 \mathrm{~mol} \%[\operatorname{Er}(\uparrow) \operatorname{Er}(\uparrow)]$ and $6.7 \mathrm{~mol} \%[\operatorname{Er}(\uparrow) \operatorname{Er}(\uparrow)-$ $\operatorname{Er}(\uparrow) \operatorname{Er}(\uparrow)]$ feature a clear semiconductor character with very similar gaps in the "majority" and the "minority" spin-density of states. These gaps refer, of course, to the corresponding spin-up and spin-down electronic configurations, respectively. As we can also see, spin-up and spin-down states are obviously asymmetric, particularly near the Fermi energy level where the DOS is attributed mainly to $\mathrm{Er}^{+3}$ This picture is in accord with our pervious our outcomes suggesting that the magnetic character of $\mathrm{Er}^{+3}$ :YSZ should be solely attributed to the $\mathrm{Er}^{+3}$ ions incorporated in the crystal of $\mathrm{c}-\mathrm{ZrO}_{2}$. Also, it is interesting to

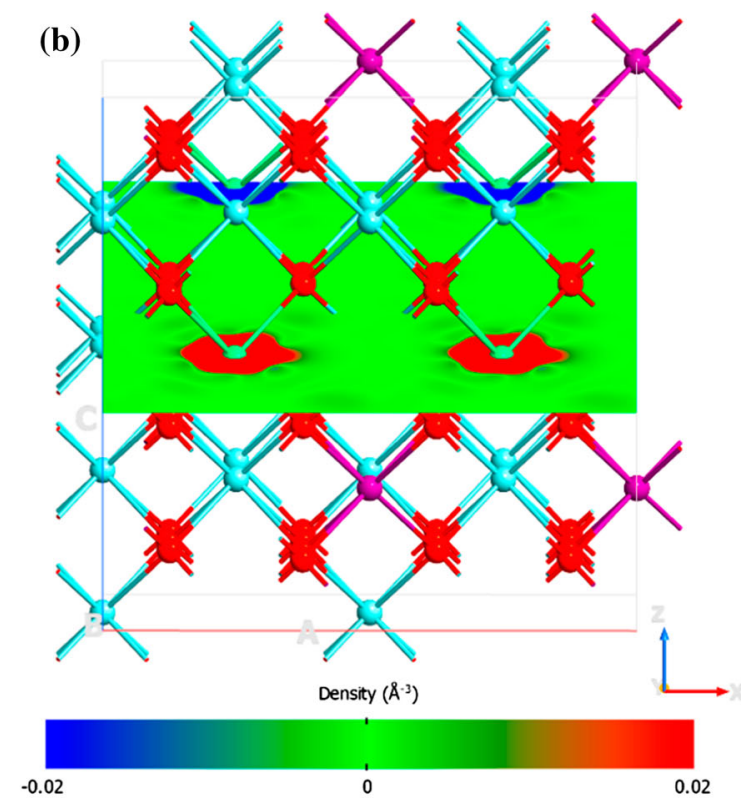

Figure 3 Cut plane of the spin density contribution of the $\mathrm{YSZ}-\mathrm{Er}_{2} \mathrm{O}_{3}$. The Er positions are in the cut plane of the square erbium ions in green, yttrium ions in purple, zirconium ions in blue, and oxygen ions in red. 

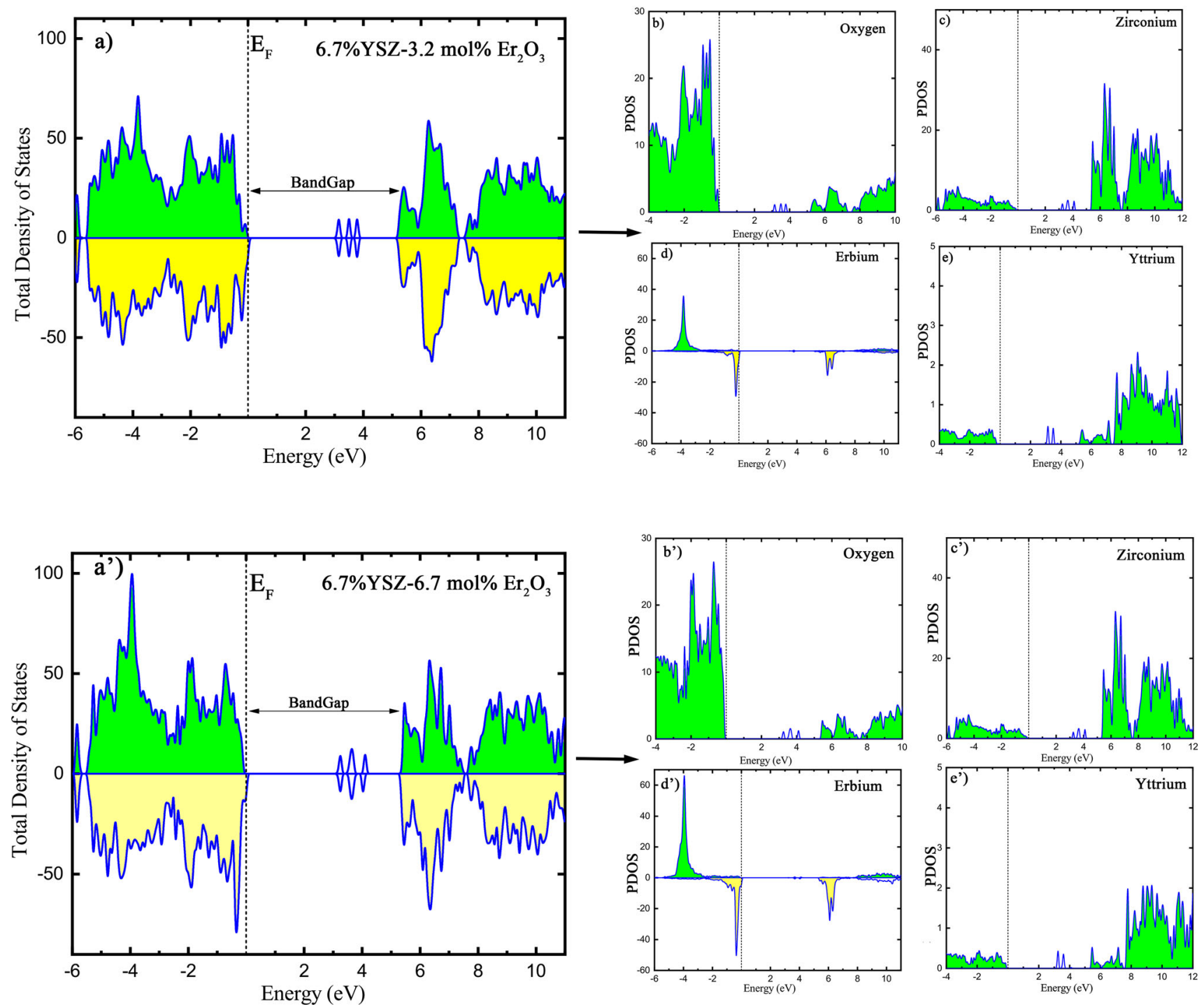

Figure 4 a, a' Total density of states (DOS) and projected density of states (PDOS) of the atoms $\left[\left(\mathbf{b}, \mathbf{b}^{\prime}\right) \mathrm{O},\left(\mathbf{c}, \mathbf{c}^{\prime}\right) \mathrm{Zr},\left(\mathbf{d}, \mathbf{d}^{\prime}\right) \mathrm{Er},(\mathbf{e}\right.$, $\left.\mathbf{e}^{\prime}\right) \mathrm{Y}$ ] of $\mathrm{YSZ}-\mathrm{Er}_{2} \mathrm{O}_{3}$, computed using the PBE0 model. At this point it is important to stress that the reported band gap values do

stress that the top of the valence band (VB) is dominated primarily by the spin-down density, while the conduction band $(\mathrm{CB})$ is mostly populated by states attributed to $\mathrm{Zr}$ atoms with a small contribution of spin-down states coming from Er atoms (see Fig. 4c and d). Finally, the antiferromagnetic (AFM) state $\operatorname{Er}(\uparrow) \operatorname{Er}(\downarrow)$ for $3.2 \%$ of $\operatorname{Er}_{2} \mathrm{O}_{3}$ and $\operatorname{Er}(\uparrow) \operatorname{Er}(\downarrow) \operatorname{Er}(\uparrow) \operatorname{Er}(\downarrow)$ for $6.7 \%)$ has been also studied. In that case, the total DOS (not plotted here) is symmetric but remarkably similar to the ferromagnetic (FM) one. The principal differences come from Er PDOS near the Fermi energy, one half being positive and the other negative without affecting the gap values: 5.19 (5.31) eV for

not take into account the weak peaks appearing around $4 \mathrm{eV}$ of the $\mathrm{CB}$ which should be regarded as numerical artifacts due to the non-relaxed lattice constants [70, 71].

FM and 5.20 (5.37) eV for AFM at the PBE0 level of calculation (see Table 2).

\section{Conclusions}

We performed an accurate calculation of the electronic, magnetic properties of $3.2 \mathrm{~mol} \%$ and $6.7 \mathrm{~mol} \%$ erbium-doped YSZ $6.7 \mathrm{~mol} \%$ in yttria. In its most stable electronic structure, $\mathrm{Er}^{3+}: \mathrm{YSZ}$ is an antiferromagnetic semiconductor with a gap of $5.20 \mathrm{eV}$ which is about $0.4 \mathrm{meV}$ per $\mathrm{Er}$ atoms more stable with respect to the ferromagnetic spin configuration. 
Concerning the energy difference between the conduction and valence bands, a narrowing of the band gap is observed with respect to $\mathrm{YSZ}$ and $\mathrm{ZrO}_{2}$, upon $\mathrm{Er}^{+3}$ doping. Even if there is no experimental confirmation, the fact that the same behavior is observed in other alloyed semiconductors supports our predictions. This could be confirmed by experimental optical transmission measurements via vacuum-ultraviolet (VUV) and valence-band $\mathrm{x}$-ray-photoemission spectroscopies (VB-XPS). Our best estimates for the total magnetic moment of $3.2 \mathrm{~mol} \%$ and $6.7 \mathrm{~mol} \%$ in $\mathrm{Er}_{2} \mathrm{O}_{3}$ YSZ are $M_{\text {tot }}=6 \mu_{B}$ and $12 \mu_{B}$ per cell, respectively, with a local magnetic moment of $2.96 \mu_{B}$ per Er atom. In addition, we calculated on the magnetic anisotropy energy MAE that controls the observable magnetism in these systems and the magnetic anisotropy energy is found about $7.42 \mathrm{meV}$ per Er atom.

\section{Acknowledgements}

Part of this work was granted access to the HPC resources of [CCRT/CINES/IDRIS] under the allocations 2019-2020 2020-2021 [A0040807031] made by GENCI (Grand Equipement National de Calcul Intensif). We also acknowledge the "Direction du Numérique" of the "Université de Pau et des Pays de l'Adour" and the Mésocentre de Calcul Intensif Aquitain (MCIA) for the computing facilities provided. H.D. thanks ANR for the one-year postdoc position in project FOIST.

\section{References}

[1] Pearton SJ, Abernathy CR, Norton DP et al (2003) Advances in wide bandgap materials for semiconductor spintronics. Mater Sci Eng R Rep 40:137-168

[2] Kikkawa JM, Awschalom DD (2000) All-optical magnetic resonance in semiconductors. Science 287:473-476

[3] Pearton SJ, Abernathy CR, Overberg ME et al (2003) Wide band gap ferromagnetic semiconductors and oxides. J Appl Phys 93:1-13

[4] Harima H (2004) Raman studies on spintronics materials based on wide bandgap semiconductors. J Phys Condens Matter 16:S5653

[5] Akinaga H, Ohno H (2002) Semiconductor spintronics. IEEE Trans Nanotechnol 1:19-31
[6] Jayachandraiah C, Sivakumar K, Divya A, Krishnaiah G (2016) Erbium induced magnetic properties of $\mathrm{Er} / \mathrm{ZnO}$ nanoparticles. AIP Conf Proc 1731:050116

[7] Jungwirth T, Sinova J, Manchon A et al (2018) The multiple directions of antiferromagnetic spintronics. Nat Phys 14:200-203

[8] Wolf SA, Awschalom DD, Buhrman RA et al (2001) Spintronics: a spin-based electronics vision for the future. Science 294:1488-1495

[9] Pearton SJ, Abernathy CR, Thaler GT et al (2004) Wide bandgap GaN-based semiconductors for spintronics. J Phys: Condens Matter 16:209-245

[10] Grün H, Berer T, Bauer-Marschallinger J et al (2004) Spintronics: fundamentals and applications. Rev Mod Phys 76:323-410

[11] Furdyna JK (1988) Diluted magnetic semiconductors. J Appl Phys 64:29-64

[12] Ueno K, Nakamura S, Shimotani H et al (2008) Electricfield-induced superconductivity in an insulator. Nat Mater $7: 855-858$

[13] Ahn CH, Triscone JM, Mannhart J (2003) Electric field effect in correlated oxide systems. Nature 424:1015-1018

[14] Furdyna JK (1986) Diluted magnetic semiconductors: Issues and opportunities. J Vac Sci Technol A 4:2002-2009

[15] Hota RL, Tripathi GS, Misra PK (1994) Theory of magnetization in IV-VI based diluted magnetic semiconductors. J Appl Phys 75:5737-5739

[16] Berciu M, Jankó B (2003) Nanoscale Zeeman localization of charge carriers in diluted magnetic semiconductor-permalloy hybrids. Phys Rev Lett 90:4

[17] Samanta A, Goswami MN, Mahapatra PK (2018) Magnetic and electric properties of Ni-doped $\mathrm{ZnO}$ nanoparticles exhibit diluted magnetic semiconductor in nature. J Alloy Compd 730:399-407

[18] Gu G, Zhao G, Lin C et al (2018) Asperomagnetic order in diluted magnetic semiconductor $(\mathrm{Ba}, \mathrm{Na})(\mathrm{Zn}, \mathrm{Mn})_{2} \mathrm{As}_{2}$. Appl Phys Lett 112:032402

[19] Heiroth S, Ghisleni R, Lippert T et al (2011) Optical and mechanical properties of amorphous and crystalline yttriastabilized zirconia thin films prepared by pulsed laser deposition. Acta Mater 59:2330-2340

[20] Ostanin S, Craven AJ, McComb DW et al (2000) Effect of relaxation on the oxygen $\mathrm{K}$-edge electron energy-loss nearedge structure in yttria-stabilized zirconia. Phys Rev B Condens Matter Mater Phys 62:14728-14735

[21] Götsch T, Bertel E, Menzel A et al (2018) Spectroscopic investigation of the electronic structure of yttria-stabilized zirconia. Phys Rev Mater 2:1-15 
[22] Xia X, Oldman R, Catlow R (2009) Computational modeling study of bulk and surface of yttria-stabilized cubic zirconia. Chem Mater 21:3576-3585

[23] Nicoloso N, Lobert A, Leibold B (1992) Optical absorption studies of tetragonal yttria-stabilized zirconia. Sens Actuators 8:253-256

[24] Parkes MA, Tompsett DA, D’Avezac M et al (2016) The atomistic structure of yttria stabilised zirconia at $6.7 \mathrm{~mol} \%$ : an ab initio study. Phys Chem Chem Phys 18:31277-31285

[25] Marcaud G, Matzen S, Alonso-Ramos C et al (2018) Highquality crystalline yttria-stabilized-zirconia thin layer for photonic applications. Phys Rev Mater 2:35202

[26] Marcaud G, Serna S, Panaghiotis K et al (2020) Third-order nonlinear optical susceptibility of crystalline oxide yttriastabilized zirconia. Photonics Res 8:110-120

[27] Chislov AS, Borik MA, Kulebyakin AV et al (2019) Comparison of mechanical properties of zirconia crystals partially stabilized with yttria and gadolinia. J Phys Conf Ser 1347:012059

[28] Bogicevic A, Wolverton C (2003) Nature and strength of defect interactions in cubic stabilized zirconia. Phys Rev B Condens Matter Mater Phys 67:024106

[29] Stapper G, Bernasconi M, Nicoloso N, Parrinello M (1999) $\mathrm{Ab}$ initio study of structural and electronic properties of yttria-stabilized cubic zirconia. Phys Rev B Condens Matter Mater Phys 59:797-810

[30] Qin R, Zeng HC (2019) Confined transformation of UiO-66 nanocrystals to yttria-stabilized zirconia with hierarchical pore structures for catalytic applications. Adv Func Mater 29:1903264

[31] Meng X, Xu J, Zhu J et al (2020) Porous yttria-stabilized zirconia ceramics with low thermal conductivity via a novel foam-gelcasting method. J Mater Sci 55:15106-15116http s://doi.org/10.1111/jace.12074

[32] Badwal SPS (1992) Zirconia-based solid electrolytes: microstructure, stability and ionic conductivity. Solid State Ionics 52:23-32

[33] Dixon JM, LaGrange LD, Merten U et al (1963) Electrical resistivity of stabilized zirconia at elevated temperatures. J Electrochem Soc 110:276

[34] Yoshimura M (1988) Phase stability of zirconia. Am Ceram Soc Bull 67:1950-1955

[35] Cross M, Varhue W (2003) Visible light emission from erbium doped yttria stabilized zirconia. Mater Res Soc Symp Proc 789:239-244

[36] Greenberg E, Katz G, Reisfeld R et al (1982) Radiative transition probabilities of $\mathrm{Er}^{3+}$ in yttria stabilized cubic zirconia crystals. J Chem Phys 77:4797-4803

[37] Yugami H, Koike A, Ishigame M, Suemoto T (1991) Relationship between local structures and ionic conductivity in
$\mathrm{ZrO}_{2}-\mathrm{Y}_{2} \mathrm{O}_{3}$ studied by site-selective spectroscopy. Phys Rev B 44:9214

[38] Merino RI, Orera VM, Cases R, Chamarro MA (1991) Spectroscopic characterization of $\mathrm{Er}^{3+}$ in stabilized zirconia single crystals. J Phys Condens Matter 3:8491-8502

[39] Arashi H (1972) Absorption spectrum of $\mathrm{Er}^{3+}$ ions in cubic zirconia. Physica Status Solidi (a) 10:107-112

[40] Ryabochkina PA, Sidorova NV, Ushakov SN, Lomonova EE (2014) Spectroscopic properties of erbium-doped yttria-stabilised zirconia crystals. Quantum Electron 44:135-137

[41] Savoini B, Muoz-Santiuste JE, González R et al (2001) Upconversion luminescence of $\mathrm{Er}^{3+}$-doped YSZ single crystals. J Alloy Compd 323-324:748-752

[42] Ruiz-Caridad A, Marcaud G, Ramirez JM et al (2020) Erbium-doped yttria-stabilised zirconia thin films grown by pulsed laser deposition for photonic applications. Thin Solid Films 693:137706

[43] Wang X, Tan X, Xu S et al (2020) Preparation and upconversion luminescence of Er-doped yttria stabilized zirconia single crystals. J Lumin 219:116896

[44] Ruiz-Caridad A, Collin S, Alonso-Ramos C et al (2020) Erbium-doped yttria-stabilized zirconia thin layers for photonic applications. IEEE J Quantum Electron 56:1-7

[45] Lin T, Zhang X, Xu J et al (2013) Strong energy-transferinduced enhancement of $\mathrm{Er}^{3+}$ luminescence in $\mathrm{In}_{2} \mathrm{O}_{3}$ nanocrystal codoped silica films. Appl Phys Lett 103:181906

[46] Wu J, Coffer JL (2007) Strongly emissive erbium-doped tin oxide nanofibers derived from sol gel/electrospinning methods. J Phys Chem C 111:16088-16091

[47] Aleksanyan E, Kirm M, Feldbach E et al (2017) Luminescence properties of $\mathrm{Er}^{3+}$ doped zirconia thin films and $\mathrm{ZrO}_{2} /$ $\mathrm{Er}_{2} \mathrm{O}_{3}$ nanolaminates grown by atomic layer deposition. Opt Mater 74:27-33

[48] Parkes MA, Refson K, Davezac M et al (2015) Chemical descriptors of yttria-stabilized zirconia at low defect concentration: an ab initio study. J Phys Chem A 119:6412-6420

[49] Ioffe AI, Rutman DS, Karpachov SV (1978) On the nature of the conductivity maximum in zirconia-based solid electrolytes. Electrochim Acta 23:141-142

[50] Blöchl PE (1994) Projector augmented-wave method. Phys Rev B 50:17953-17979

[51] Perdew JP, Burke K, Ernzerhof M (1996) Generalized gradient approximation made simple. Phys Rev Lett 77:3865-3868

[52] Kresse G, Joubert D (1999) From ultrasoft pseudopotentials to the projector augmented-wave method. Phys Rev B 59:1758-1775

[53] Kresse G, Furthmüller J (1996) Efficient iterative schemes for ab initio total-energy calculations using a plane-wave 
basis set. Phys Rev B Condens Matter Mater Phys 54:11169-11186

[54] Kresse G, Furthmiiller J (1996) Efficiency of ab-initio total energy calculations for metals and semiconductors using a plane-wave basis set. Comput Mater Sci 6:15-50

[55] Pack JD, Monkhorst HJ (1976) Special points for brillouinzone integrations. Phys Rev B 13:5188-5192

[56] Bader RFW (1990) Atoms in molecules: a quantum theory. Oxford University Press, Oxford

[57] Henkelman G, Arnaldsson A, Jónsson H (2006) A fast and robust algorithm for Bader decomposition of charge density. Comput Mater Sci 36:354-360

[58] Allouche A (2012) Software News and Updates Gabedit-a graphical user interface for computational chemistry softwares. J Comput Chem 32:174-182

[59] Anisimov VI, Aryasetiawan F, Lichtenstein AI (1997) Firstprinciples calculations of the electronic structure and spectra of strongly correlated systems: The LDA + U method. J Phys Condens Matter 9:767-808

[60] Peng H, Scanlon DO, Stevanovic V et al (2013) Convergence of density and hybrid functional defect calculations for compound semiconductors. Phys Rev B Conden Matter Mater Phys 88:1-7

[61] Denawi H, Koudia M, Hayn R et al (2018) On-surface synthesis of spin crossover polymeric chains. J Phys Chem C 122:15033-15040

[62] Denawi H, Abel M, Hayn R (2019) Magnetic polymer chains of transition metal atoms and zwitterionic quinone. J Phys Chem C 123:4582-4589

[63] Njifon IC, Bertolus M, Hayn R, Freyss M (2018) Electronic structure investigation of the bulk properties of uranium- plutonium mixed oxides $(\mathrm{U}, \mathrm{Pu}) \mathrm{O}_{2}$. Inorg Chem 57:10974-10983

[64] Saoudi H, Denawi H, Benali A et al (2018) Preparation and electron correlation effects of the perovskite $\mathrm{La} 0.8 \mathrm{Ca} 0.1 \mathrm{~Pb} 0.1 \mathrm{Fe} 1-\mathrm{xCoxO} 3(0 \leq \mathrm{x} \leq 0.20)$. Solid State Ionics 324:157-162

[65] Liechtenstein AI, Anisimov VI, Zaanen J (1995) Densityfunctional theory and strong interactions: orbital ordering in Mott-Hubbard insulators. Phys Rev B 52:5467-5471

[66] Dovesi R, Erba A, Orlando R et al (2018) Quantum-mechanical condensed matter simulations with crystal. Wiley Interdiscip Rev Comput Mol Sci 8:e1360

[67] French RH, Glass SJ, Ohuchi FS et al (1994) Experimental anti theoretical determination of the electronic structure and optical properties of three phases of $\mathrm{ZrO}_{2}$. Phys Rev B 49:5133

[68] Králik B, Chang EK, Louie SG (1998) Structural properties and quasiparticle band structure of zirconia. Phys Rev B Condens Matter Mater Phys 57:7027-7036

[69] Ceperley DM, Alder BJ (1980) Ground state of the electron gas by a stochastic method. Phys Rev Lett 45:566-569

[70] Ricca C, Ringuedé A, Cassir M et al (2015) Revealing the properties of the cubic $\mathrm{ZrO}_{2}$ (111) surface by periodic DFT calculations: reducibility and stabilization through doping with aliovalent $\mathrm{Y}_{2} \mathrm{O}_{3}$. RSC Adv 5:13941-13951

[71] Mohamad R, Chen J, Ruterana P (2020) The effect of $\mathrm{N}$-vacancy and in aggregation on the properties of InAlN. Comput Mater Sci 172:109384

Publisher's Note Springer Nature remains neutral with regard to jurisdictional claims in published maps and institutional affiliations. 